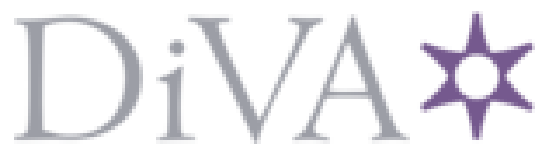

http://www.diva-portal.org

This is the published version of a paper published in Health and Place.

Citation for the original published paper (version of record):

Ng, N., Häggström Lundevaller, E., Malmberg, G., Edvinsson, S. (2020)

Income inequality and old-age mortality in Sweden: do regional development and lagged effect matter?

Health and Place, 64: 102384

https://doi.org/10.1016/j.healthplace.2020.102384

Access to the published version may require subscription.

N.B. When citing this work, cite the original published paper.

Permanent link to this version:

http://urn.kb.se/resolve?urn=urn:nbn:se:umu:diva-174851 


\title{
Income inequality and old-age mortality in Sweden: do regional development and lagged effect matter?
}

\author{
Nawi Ng ${ }^{\text {a,b,c,*, Erling Lundevaller }}{ }^{c}$, Gunnar Malmberg ${ }^{\text {c, }}$, Sören Edvinsson ${ }^{c}$ \\ ${ }^{a}$ Department of Epidemiology and Global Health, Faculty of Medicine, Umeå University, Sweden \\ ${ }^{\mathrm{b}}$ Global and Public Health, School of Public Health and Community Medicine, Institution of Medicine, Sahlgrenska Academy, University of Gothenburg, Sweden \\ ${ }^{c}$ Centre for Demographic and Ageing Research, Umeå University, Sweden \\ d Department of Geography, Umeå University, Sweden
}

\section{A R T I C L E I N F O}

\section{Keywords:}

Income inequality

Gini index

Old-age mortality

Lagged effects

Regional effects

Sweden

\begin{abstract}
A B S T R A C T
We designed a retrospective cohort study for exploring the impact of municipality-level income inequality, based on the Gini 1986, 2004 indices, on all-cause old-age mortality among the older Swedish population during 2005-2009. We controlled for the confounding effects of individual and regional correlates and the lag effects of inequality by using multilevel logistic regression. The effects of income inequality were not consistent across age cohorts and, among the youngest cohorts, were negligible. This study reiterates that individual-level economics rather than the immediate or lagged effects of income inequality matter more for old-age mortality, even after controlling for individual and regional factors.
\end{abstract}

\section{Introduction}

A multitude of studies demonstrate that socioeconomic conditions have a strong impact on health, even in economically advantaged welfare societies. Wilkinson and Pickett argue that socioeconomic inequality in society has an independent effect on health and adds to increasing health gaps between the rich and the poor (Wilkinson and Pickett, 2009). Since the 1980s, income and wealth inequality has increased substantially in many countries, not least in Sweden (Pickett and Wilkinson, 2014). However, previous research on the effect of income inequality on health provides an ambiguous picture. Most studies confirming the hypothesis about the deleterious effects of income inequality on mortality have either been on a national level or within the US and the UK (Arber et al., 2014; Martinson, 2012). Studies on the comparatively egalitarian Nordic countries, however, have pointed in different directions. Most Nordic studies have not confirmed the hypothesis, but others provide evidence of the hazardous effect of income inequality on health (Dahl et al., 2006; Edvinsson et al., 2013; Gerdtham and Johannesson, 2004; Henriksson et al., 2006).

The absolute income hypothesis, also called the "concavity effect", tests the consequence of distribution of individual incomes on health (Wagstaff and van Doorslaer, 2000)(Subramanian and Kawachi, 2004). The marginal positive effect of increasing income is the greatest in lower-income groups. Incomes for those in poor groups are usually higher in more equal societies, and for this reason their group general health is better. The effect on health is therefore mainly an effect of individual economy and not one of inequality in itself. Wilkinson and Pickett, on the other hand, are more interested in how inequality in society influences health and mortality beyond the effect of individual economy (Wilkinson and Pickett, 2006). The income inequality effect is based on the assumption that inequality in itself has an independent effect, making egalitarian societies healthier.

The wealth of research on income inequality and health has always been challenged by methodological issues. Subramanian and Kawachi warned of a number of confounders that might threaten the validity of the association between income inequality and health (Subramanian and Kawachi, 2004). These threats include confounding by individual income, educational attainment (and other individual socioeconomic correlates), racial composition, regional effects, and potential lag effects of income inequality on health.

The potential confounding effect of regional characteristics can be substantial if important differences between geographical units exist; different economic levels in a society; for example. A richer society is reasonably beneficial for all, even individuals with less economic resources. Several studies have shown the importance of contextual factors at the societal level - such as economic standard and structure, access to

\footnotetext{
* Corresponding author. Department of Epidemiology and Global Health, Faculty of Medicine, Umeå University, Sweden.

E-mail addresses: nawi.ng@umu.se (N. Ng), erling.lundevaller@umu.se (E. Lundevaller), gunnar.malmberg@umu.se (G. Malmberg), soren.edvinsson@umu.se (S. Edvinsson).
} 
infrastructure, and cost of living - on the association between income inequality and mortality (Clough-Gorr et al., 2015; Elstad, 2011; Henriksson et al., 2010). In the Swedish context, such differences in contextual factors between the largest cities and the rural parts of Sweden are substantial, representing very different settings when it comes to population size, economy, and living standards. Therefore, multilevel regression models which take into account higher-level geographical area characteristics, e.g. regional characteristics, should be applied to differentiate the effects of individual income and societal inequality on health outcomes.

Only a few studies have incorporated the lagged effects of income inequality on health (Blakely et al., 2000; Subramanian and Kawachi, 2004). A couple of these studies identified the strongest effect of income inequality on mortality at a time lag of 15 years (Subramanian and Kawachi, 2004); while Zheng (2012) found that the effect peaks at 7 years and diminishes after 12 years. Mellor and Milyo (2003) found no association between lagged income inequality and mortality after controlling for regional characteristics (Mellor and Milyo, 2003). In many of the studies it is impossible to control for any changes in inequality levels in residential area and individual income that occurred at earlier life stages. This might have resulted in an underestimation of the effects of inequality.

Most of the previous studies also focused on the working-age population, as the effects of income inequality might be more evident and stronger at these ages. Health problems, however, are more prominent among older people, and advantages or disadvantages may be accumulated throughout the course of life (Dannefer, 2003). The effects of inequality among older populations have rarely been investigated.

The present study utilised Swedish longitudinal micro-data covering the entire Swedish population for the period 1986-2009. The overarching aim of this study was to explore the impact of income inequality at the municipality level among the older Swedish population (aged 65-92 years in 2004) on the overall mortality rate during 2005-2009. We hypothesised that: (i) the effects of income inequality at the municipality level on old-age mortality were not homogenous across different age cohorts of older people; and (ii) the effects of individuallevel income on old-age mortality (absolute income) were stronger than the municipality-level income inequality (relative income). Moreover, this paper attempts to fill the knowledge gaps related to two challenging methodological issues by researching income inequality and health, as described by Subramanian and Kawachi (2004) (Subramanian and Kawachi, 2004)-a confounding of regional effects and potential lag effects of income inequality. First, we hypothesised that the effect of income inequality at the municipality level on old-age mortality would change when individual and contextual conditions at the municipality level were controlled for. Second, we hypothesised that income inequality in the municipality of residence has long-term effects on old-age mortality. In this study, we used municipality as the level of aggregation for assessing the effects of income inequality. Municipalities represent formal political units where much of the practical arrangements of people's lives are organized. Furthermore, it represents an important spatial unit where people identify themselves. Other levels of aggregation such as economic regions and neighbourhoods represent somewhat different aspects.

\section{Methods}

\section{Study population and data sources}

This study is designed as a retrospective cohort study. The study utilised the Linnaeus database, maintained by the Centre for Demographic and Ageing Research (CEDAR) at Umeå University in Sweden. The Linnaeus database is an anonymised dataset which links different administrative population registers such as the LISA database (a longitudinal database for health insurance and labour market), death, and hospitalisation registers. Further details about the Linnaeus database can be found elsewhere (Malmberg et al., 2010). In this study, we utilised (i) the LISA database for 2004; (ii) the national socioeconomic survey from 1986 to 2004; and (iii) the death register from the Swedish National Board of Health and Welfare for the period 2005-2009.

During 1986-2009, a small number of municipalities were merged or split up. In this study, we used the 2007 administrative borders to identify the geographical coordinates of each individual's residence, which were later used to identify the municipality where the individual lived in 1984 and 2004. The study is based on 290 municipalities.

\section{Independent variables}

In the analysis, we controlled for both individual- and municipalitylevel variables. The individual-level variables included year of birth, whether the person had a partner (either married or cohabitating), disposable income at individual level, and highest level of education. For the income variable, we used the individualised disposable household income in Swedish SEK, divided into five equal categories on a national level from very high to very low. While this individual-level household income offers information on the absolute value, it does not consider the differences in costs of living across municipalities.

The municipality level variables include median municipality income, Gini index, and region family, i.e. a classification of municipalities based on their population structure, economic level, costs of living, occupational structure and the availability of infrastructure, as they were defined and labelled by The Swedish Agency for Economic and Regional Growth, a governmental agency (NUTEK, 2007). The region family variable includes six region types: (i) the three large cities of Stockholm, Gothenburg, and Malmö, used as the reference group in the analysis; (ii) the big cities other than the three large cities; (iii) the bigger regional centres; (iv) small regional centres; (v) small regional private sectors; and (vi) small regional public sectors. Our initial analyses indicated a clustering of different region families, particularly the largest cities, when the association between income inequality and old-age mortality was analysed; thereby making it essential to adjust the analysis using the region family variable.

The Gini index, which is a commonly used measure of income inequality, was calculated based on equivalised disposable income of the working-age population aged 30-59 years in each municipality, in accordance with Elstad (2011) (Elstad, 2011). This aggregate index provides a general description of the inequality level in each municipality. Our choice to calculate the Gini coefficient based on income in the working-age population yielded an index which was less dependent on the age structure and composition of populations outside working age; those who might have lower incomes which could vary considerably across municipalities. This, however, made our Gini index not directly compatible with the typical Gini index, which is based on the whole population in a geographical/administrative area. Nevertheless, we observed a strong correlation between the two measures of Gini indices, i.e. the one based on the whole population and the one based only on the working-age population. To address municipalities with outlier Gini values and the possible non-linear effect of Gini on old-age mortality, we categorised the Gini index into quintiles.

We obtained these individual and municipality level variables for the year 2004 from the LISA database. We also calculated the lag-terms for the Gini index based on the 1986 LISA data to assess the long-term effects of municipality-level income inequality on old-age mortality.

\section{Outcome variable}

The main outcome variable in this study is all-cause mortality among older people aged 65-92 years at baseline in 2004 during the five years that followed: 2005-2009. 


\section{Statistical analysis}

We stratified the analyses by sex and birth cohort (respondents born 1912-1919, 1920-1929, and 1930-1939) - six groups in total. We built three different multilevel logistic regression models to assess the effect of income inequality at the 2004 municipality level, reflected in the Gini index, on old-age mortality during 2005-2009. Based on the quintile of Gini index distribution, municipality was further sub-grouped into five groups on a low to high Gini index scale. In our analyses, we used the 3rd quintile as the reference categories, against which the 1st/2nd as well as the 4 th $/ 5$ th quintiles were compared. In the first model, we controlled the analysis for all individual-level variables. In the second model, we added municipality-level variables including municipality median income and region family. In the last model, we added different Gini lagged terms. We used the likelihood-ratio test to assess the goodness of fit of the different models we specified in the study. In this article, we only present the 1986 Gini lagged term, which represents an 18-23-year lagged effect of Gini on old age mortality. The results of the other time lags are available upon request.

\section{Results}

In this study, we included 1,484,852 individuals born between 1912 and 1930 (646,386 men and 838,466 women) in three different cohorts: 1912-1919, 1920-1929, and 1930-1939 (Table 1). As the number of missing data in the population register data was very small $(<0.5 \%)$, we were able to use complete case in all our analyses. In all cohorts, more men than women had a partner (either married or cohabiting). Men had consistently higher individualised disposable incomes in 2004 across all cohorts, with the greatest difference observed in the younger cohort. A total of 344,999 individuals (162,940 men and 182,059 women) died during 2004-2009, yielding an annual mortality rate that went from 5.2 per 1000 men in the youngest cohort, to 41.2 per 1000 men in the oldest cohort. The corresponding numbers for women were 3.3 and 32.4 per 1,000 , respectively.

During the late 20th and early 21st centuries, both income inequality and disposable income increased substantially in all municipalities. Municipalities became richer, but also more unequal. Additionally, as the mean disposable income and Gini in municipalities became more dispersed between 1986 and 2004, so did the differences in mean disposable income and Gini between municipalities become wider (Table 2 and Fig. 1). We observed substantial growth in income and inequality in municipalities located in the big city regions (in Stockholm, Gothenburg, Malmö and the big city areas). For municipalities in the other region families, the growth in mean disposable income and inequality was comparatively small. Since a large part of the population lived in the big city regions, they have a strong impact on the analyses. Thus, it is important that we control for region family in subsequent
Table 2

Characteristics of the municipalities (for all municipalities).

\begin{tabular}{lcc}
\hline Municipality-level variables & Year 1986 & Year 2004 \\
\hline Aggregated individualised disposable income in tSEK at & municipality level \\
Mean (SD) & $593(50)$ & $1325(90)$ \\
Median (interquartile range) & $590(556-621)$ & $1309(1263-1364)$ \\
Mean (SD) for each region family & \\
Small region public sector & $573.1(27.3)$ & $1310.6(60.4)$ \\
Small region private sector & $572.0(27.1)$ & $1.320 .0(64.8)$ \\
Small region centres & $571.7(28.8)$ & $1386.3(73.6)$ \\
Bigger region centres & $579.1(30.4)$ & $1400.7(61.4)$ \\
Big city area & $623.6(56.9)$ & $1552.1(249.8)$ \\
Stockholm, Malmö, & $662.7(33.7)$ & $1579.4(188.6)$ \\
Gothenburg & & \\
Gini index at municipality level & \\
Mean (SD) & $0.2128(0.0119)$ & $0.2929(0.0366)$ \\
Median (interquartile range) & 0.2110 & 0.2848 \\
& $(0.2036-0.2223)$ & $(0.2669-0.309)$ \\
Mean (SD) for each region family & \\
Small region public sector & $0.2133(0.0101)$ & $0.2583(0.0145)$ \\
Small region private sector & $0.2111(0.0118)$ & $0.2669(0.0246)$ \\
Small region centres & $0.2150(0.0128)$ & $0.2728(0.0248)$ \\
Bigger region centres & $0.2128(0.0134)$ & $0.2711(0.0150)$ \\
Big city area & $0.2197(0.0132)$ & $0.3037(0.0412)$ \\
Stockholm, Malmö, & $0.2174(0.0084)$ & $0.3362(0.0226)$ \\
Gothenburg & & \\
\hline
\end{tabular}

Notes: The region family represented municipalities with different population structure, economic level, costs of living, occupational structure, and the availability of infrastructure.

analyses.

We started with a naïve model, in which we estimated the effects of municipality-level income inequality and mortality and adjusted the results only by the year of birth (results shown in Appendix 1 and 2). In the first model, we focused on the associations between Gini and old-age mortality when all the individual variables were controlled for. Comparing the six age and sex groups, we found some differences, as shown in Table 3 (full models are available in Appendices 3 and 4). We observed higher odds of mortality among men and women who lived in the more equal municipalities (quintiles 1 and 2); this was a consistent finding across all age cohorts, except for men aged 65-74 years, for whom the results were not significant. Living in municipalities with a high inequality level (quintile 5) had a significant association with mortality among men and women aged 65-74 and men aged 75-84, but not in the oldest age group. For women aged 65-74, living in the most unequal municipalities increased mortality the most. Older women aged 85-92 who lived in municipalities with the highest inequality showed a significantly lower mortality risk. It was only among men aged 65-74 that we observed a tendency towards a hierarchical trend of higher mortality in more unequal municipalities. Instead, there is the opposite hierarchical order (higher mortality in the most equal municipalities) in the oldest age group and for women aged 75-84. Inequality seems to

Table 1

Characteristics of the study subject.

\begin{tabular}{|c|c|c|c|c|c|c|}
\hline \multirow{2}{*}{ Variables } & \multicolumn{2}{|c|}{$\begin{array}{l}\text { Youngest cohort } \\
\text { 65-74 years (born 1930-1939) }\end{array}$} & \multicolumn{2}{|c|}{$\begin{array}{l}\text { Middle cohort } \\
75-84 \text { years (born 1920-1929) }\end{array}$} & \multicolumn{2}{|c|}{$\begin{array}{l}\text { Oldest cohort } \\
\text { 85-92 years (born 1912-1919) }\end{array}$} \\
\hline & $\begin{array}{l}\text { Men } \\
\mathrm{n}=348,275\end{array}$ & $\begin{array}{l}\text { Women } \\
\mathrm{n}=384,182\end{array}$ & $\begin{array}{l}\text { Men } \\
\mathrm{n}=237,174\end{array}$ & $\begin{array}{l}\text { Women } \\
\mathrm{n}=330,913\end{array}$ & $\begin{array}{l}\text { Men } \\
\mathrm{n}=60,937\end{array}$ & $\begin{array}{l}\text { Women } \\
\mathrm{n}=123,371\end{array}$ \\
\hline \multicolumn{7}{|l|}{ Marital status in $2004(\%)$} \\
\hline Married or cohabited & 68.5 & 55.6 & 64.0 & 33.8 & 47.7 & 10.7 \\
\hline Did not have partner & 31.5 & 44.4 & 36.0 & 66.2 & 52.3 & 89.3 \\
\hline \multicolumn{7}{|c|}{ Individualised disposable income in 2004 (in tSEK) } \\
\hline Mean (SD) & $153.3(207.5)$ & $139.6(154.8)$ & $126.1(108.3)$ & $119.3(88.7)$ & $122.7(109.6)$ & $114.1(125.9)$ \\
\hline $\begin{array}{l}\text { Median } \\
\quad \text { (interquartile range) }\end{array}$ & $\begin{array}{l}131.3 \\
(108.9,167.9)\end{array}$ & $\begin{array}{l}120.2 \\
(103.2,150.8)\end{array}$ & $\begin{array}{l}111.1 \\
(94.6,134.5)\end{array}$ & $\begin{array}{l}109.1 \\
(94.1,124.3)\end{array}$ & $\begin{array}{l}107.5 \\
(90.2,129.5)\end{array}$ & $\begin{array}{l}106.1 \\
(92.3,117.9)\end{array}$ \\
\hline \multicolumn{7}{|l|}{ Deaths and follow-up during 2004-2009 } \\
\hline Total deaths & 42,778 & 30,061 & 80,190 & 81,968 & 39,972 & 70,030 \\
\hline Total follow-up (in years) & $1,638,316$ & $1,849,917$ & 985,625 & $1,458,347$ & 193,853 & 432,024 \\
\hline Annual mortality rate per 1000 population & 5.2 & 3.3 & 16.3 & 11.2 & 41.2 & 32.4 \\
\hline
\end{tabular}




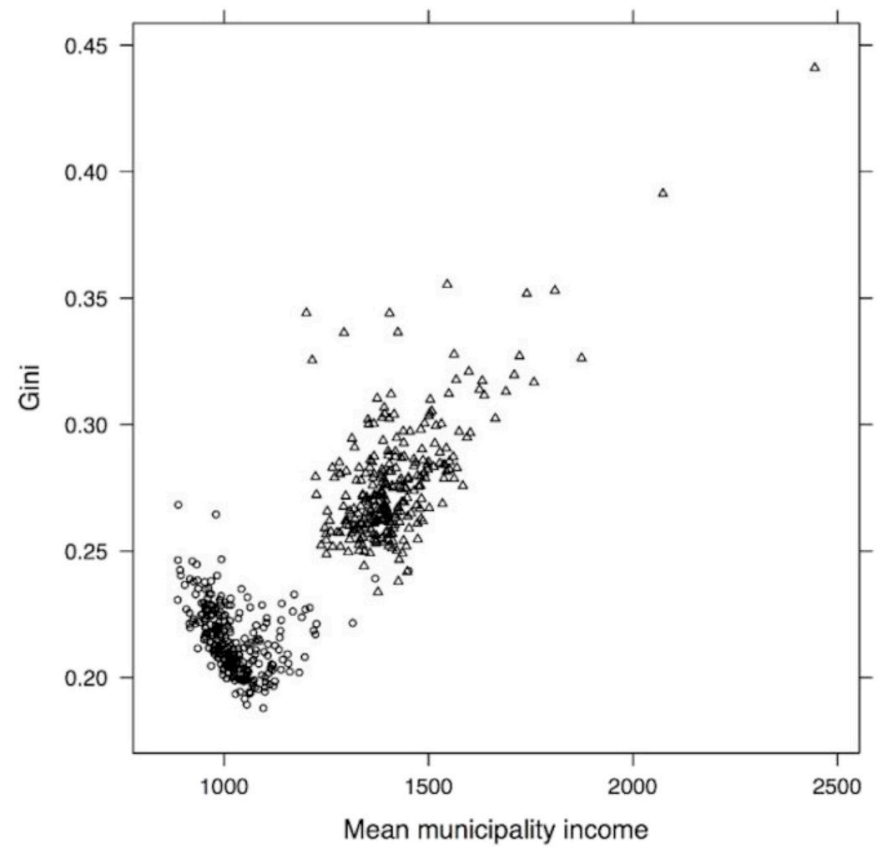

Fig. 1. Income inequality (Gini) and mean income (in tSEK, adjusted to price level in 2004) in Swedish municipalities in 1986 (circles) and 2004 (triangles) (based on individualised disposable income for working-age population).

have different associations with mortality depending on age group.

In the second model, when we introduced the context variables at municipality level, the patterns of association between income inequality and mortality changed in the youngest age group (Table 3 ). The effects of living in unequal municipalities on mortality disappeared among the youngest men and women, and the Gini variable was no longer significant for men. There was rather a tendency towards lower mortality in more unequal places. Both the oldest and middle age cohort women exhibited a negative association, indicating a lower mortality level in unequal municipalities. The results showing a higher mortality risk from living in equal municipalities among men and women remained. The contextual variable that made the greatest difference in the association between income inequality and mortality was region family, while median municipality income did not change the overall pattern in this model (full results in Appendices 5 and 6). Men and women who lived in the three big cities of Stockholm, Gothenburg, and Malmö had higher mortality than their counterparts who lived in other regions. This pattern was less clear in the oldest age group.

In the final model, we included municipality-level income inequality 18 years before baseline (Gini index in 1986). Most of the associations in Model 2 that related to the 2004 inequality level remained, albeit sometimes diluted (Table 3, full results in Appendix 7 and 8). Some of the effects were taken up by the conditions at time lag, but for the middle and old cohorts this did not change the findings where time lag was not considered. The lagged Gini term had no significant impact on the middle cohort, and a rather weak impact on the old cohort (without changing the basic results when only including the 2004 Gini term), after adjusting for individual-level and municipality-level variables (Fig. 2). In the youngest cohort, for both men and women, the conditions at the time lag had more power than those at the 2004 baseline. These results, however, did not change the general interpretation of the findings when only the 2004 baseline data was used. The 1986 Gini term was negatively associated with mortality.

As expected, we observed higher mortality among those with fewer years of education, and the patterns were consistent for both sexes and all age groups. Also as expected, age/birth cohort was highly significant in relation to mortality, with a lower risk of mortality among men and women in younger cohorts in all age groups. Those who were married at the 2004 baseline had a lower risk of mortality (for both sexes), and the effects were much greater among the younger cohort and among men. The association between individualised disposable income and mortality showed the pattern we expected in the young and middle cohorts, whilst the effect among the oldest cohort was negligible. The LikelihoodRatio test (LR-test) indicated that our final full model reported in Table 3 had the lowest likelihood and Akaike Information Criterion compared to the other models (Appendix 9), indicating the full model as the best fit model. We observed no collinearity when the region family variable was included in the analysis in the final model, indicated by the variation inflation factor being less than 10 (Appendix 10).

\section{Discussion}

In this paper, we contribute to the discourse on income inequality and health (Bor et al., 2017; Kim, 2017; Pickett and Wilkinson, 2014; Subramanian and Kawachi, 2004; Wilkinson and Pickett, 2006) by analysing the impacts of income inequality on the Swedish population at municipality level, as measured by the Gini index, and the risk of old-age mortality using register data. Using multilevel analysis, we assessed the association between the Gini coefficient and old-age mortality, controlling for individual-level variables (Model 1), contextual-level variables including region family and median income of municipality (Model 2), and a lagged-term of Gini index 18 years before baseline (Model 3).

A couple of main findings have emerged from our study. First, the effects of income inequality on mortality were not consistent across different age cohorts. Living in unequal areas was connected to lower mortality among women in the oldest cohort only. In contrast, we observed a higher mortality level in men and women in the middle and oldest cohorts among those who live in the unequal areas, once individual-level and municipality-level variables have been adjusted for. The overall effect of income inequality on mortality among the youngest men and women, however, seems negligible. Additionally, It is only in the youngest cohort that we find a significant change in the associations when the region family variable is included in the analysis. Second, individual income has a strong association with survival at the individual level: higher income is associated with lower mortality. Third, the inclusion of regional characteristics at municipality level, particularly region family, affects the observed association between municipalitylevel Gini and mortality after adjustments for individual-level variables; including year of birth, having a partner, disposable income at individual level, and highest level of education. Fourth, most of the associations are apparent with only baseline conditions included, and the inclusion of time lags does not change the basic patterns. The situation at baseline is a good reflection of survival prospects. However, once again the youngest cohort reveals a somewhat different pattern. In the following section, we present our interpretation of these findings, as well as the potential confounding roles of municipality-level variables and lag effects of income inequality on health and mortality.

\section{The impacts of income inequality and old-age mortality}

When using the Gini coefficient as a continuous index, Edvinsson et al. (2013) found a moderate positive association between Gini and mortality in Swedish municipalities in 2006 for the age group 65-74 (Edvinsson et al., 2013). The present study, which extends the previous analysis to older age groups and a longer follow-up period, does not confirm the previous results. In this study, we categorised the Gini index into quintiles and analysed men and women separately. By extending the follow-up period for mortality and controlling for other contextual variables in order to take into account compositional differences between municipalities, we obtained different results from those reported by Edvinsson et al., in 2013 (Edvinsson et al., 2013). Studies with short follow-up times are more sensitive to migration close to death. Moreover, Edvinsson et al. (2013) did not study the older age groups (75-84 
Municipality-level income inequality and old-age mortality among older Swedish men and women.

\begin{tabular}{|c|c|c|c|c|c|c|}
\hline & \multicolumn{3}{|l|}{ Men } & \multicolumn{3}{|l|}{ Women } \\
\hline & $\begin{array}{l}\text { Youngest cohort } \\
65-74 \text { years (born } \\
1930-1939 \text { ) }\end{array}$ & $\begin{array}{l}\text { Middle cohort } \\
75-84 \text { years (born } \\
1920-1929 \text { ) }\end{array}$ & $\begin{array}{l}\text { Oldest cohort } \\
\text { 85-92 years (born } \\
1912-1919)\end{array}$ & $\begin{array}{l}\text { Youngest cohort } \\
65-74 \text { years (born } \\
1930-1939 \text { ) }\end{array}$ & $\begin{array}{l}\text { Middle cohort } \\
75-84 \text { years (born } \\
1920-1929 \text { ) }\end{array}$ & $\begin{array}{l}\text { Oldest cohort } \\
\text { 85-92 years (born } \\
1912-1919 \text { ) }\end{array}$ \\
\hline \multicolumn{7}{|c|}{ Model 1: Gini in 2004 adjusted for individual-level variables } \\
\hline $\begin{array}{l}\text { Gini 2004: Q1 (Lowest } \\
\text { inequality) }\end{array}$ & $\begin{array}{l}0.026 \\
(-0.004,0.056)\end{array}$ & $\begin{array}{l}0.066^{* *} \\
(0.044,0.088)\end{array}$ & $\begin{array}{l}0.084^{* *} \\
(0.052,0.117)\end{array}$ & $\begin{array}{l}0.037^{*} \\
(0.001,0.072)\end{array}$ & $\begin{array}{l}0.078 * * \\
(0.056,0.100)\end{array}$ & $\begin{array}{l}0.052^{* *} \\
(0.028,0.077)\end{array}$ \\
\hline Gini 2004: Q2 & $\begin{array}{l}-0.014 \\
(-0.045,0.016)\end{array}$ & $\begin{array}{l}0.039 * * \\
(0.017,0.061)\end{array}$ & $\begin{array}{l}0.044^{* *} \\
(0.011,0.077)\end{array}$ & $\begin{array}{l}0.050^{* *} \\
(0.014,0.086)\end{array}$ & $\begin{array}{l}0.027^{*} \\
(0.006,0.049)\end{array}$ & $\begin{array}{l}0.022 \\
(-0.002,0.046)\end{array}$ \\
\hline Gini 2004: Q4 & $\begin{array}{l}0.017 \\
(-0.013,0.047)\end{array}$ & $\begin{array}{l}0.006 \\
(-0.015,0.028)\end{array}$ & $\begin{array}{l}0.019 \\
(-0.013,0.052)\end{array}$ & $\begin{array}{l}0.036^{*} \\
(0.001,0.071)\end{array}$ & $\begin{array}{l}-0.014 \\
(-0.036,0.008)\end{array}$ & $\begin{array}{l}-0.021 \\
(-0.046,0.003)\end{array}$ \\
\hline $\begin{array}{l}\text { Gini 2004: Q5 (Highest } \\
\text { inequality) }\end{array}$ & $\begin{array}{l}0.104 * * \\
(0.073,0.135)\end{array}$ & $\begin{array}{l}0.031 * \\
(0.007,0.055)\end{array}$ & $\begin{array}{l}-0.011 \\
(-0.046,0.024)\end{array}$ & $\begin{array}{l}0.074^{* *} \\
(0.035,0.112)\end{array}$ & $\begin{array}{l}0.001 \\
(-0.022,0.024)\end{array}$ & $\begin{array}{l}-0.072^{* *} \\
(-0.097,-0.047)\end{array}$ \\
\hline \multicolumn{7}{|c|}{ Model 2: Gini in 2004 adjusted for individual-level and municipality-level variables } \\
\hline $\begin{array}{l}\text { Gini 2004: Q1 (Lowest } \\
\text { inequality) }\end{array}$ & $\begin{array}{l}0.026 \\
(-0.006,0.059)\end{array}$ & $\begin{array}{l}0.060 * * \\
(0.036,0.085)\end{array}$ & $\begin{array}{l}0.078^{* *} \\
(0.043,0.114)\end{array}$ & $\begin{array}{l}0.037 \\
(-0.002,0.076)\end{array}$ & $\begin{array}{l}0.066^{* *} \\
(0.043,0.090)\end{array}$ & $\begin{array}{l}0.044^{* *} \\
(0.017,0.070)\end{array}$ \\
\hline Gini 2004: Q2 & $\begin{array}{l}-0.011 \\
(-0.043,0.020)\end{array}$ & $\begin{array}{l}0.034 * * \\
(0.011,0.058)\end{array}$ & $\begin{array}{l}0.050^{* *} \\
(0.015,0.084)\end{array}$ & $\begin{array}{l}0.048^{* *} \\
(0.012,0.085)\end{array}$ & $\begin{array}{l}0.018 \\
(-0.004,0.040)\end{array}$ & $\begin{array}{l}0.016 \\
(-0.008,0.041)\end{array}$ \\
\hline Gini 2004: Q4 & $\begin{array}{l}-0.005 \\
(-0.038,0.029)\end{array}$ & $\begin{array}{l}-0.008 \\
(-0.032,0.017)\end{array}$ & $\begin{array}{l}0.014 \\
(-0.024,0.051)\end{array}$ & $\begin{array}{l}-0.002 \\
(-0.043,0.039)\end{array}$ & $\begin{array}{l}-0.027^{*} \\
(-0.053,-0.001)\end{array}$ & $\begin{array}{l}-0.017 \\
(-0.046,0.012)\end{array}$ \\
\hline $\begin{array}{l}\text { Gini 2004: Q5 (Highest } \\
\text { inequality) }\end{array}$ & $\begin{array}{l}-0.038 \\
(-0.087,0.011)\end{array}$ & $\begin{array}{l}-0.017 \\
(-0.050,0.016)\end{array}$ & $\begin{array}{l}-0.007 \\
(-0.056,0.042)\end{array}$ & $\begin{array}{l}0.001 \\
(-0.053,0.054)\end{array}$ & $\begin{array}{l}-0.039^{*} \\
(-0.072,-0.006)\end{array}$ & $\begin{array}{l}-0.071^{* *} \\
(-0.108,-0.033)\end{array}$ \\
\hline \multicolumn{7}{|c|}{ Model 3: Gini in 2004 adjusted for individual-level and municipality-level variables, and lagged Gini variable in 1986} \\
\hline $\begin{array}{l}\text { Gini 2004: Q1 (Lowest } \\
\text { inequality) }\end{array}$ & $\begin{array}{l}0.015 \\
(-0.018,0.048)\end{array}$ & $\begin{array}{l}0.058^{* *} \\
(0.034,0.082)\end{array}$ & $\begin{array}{l}0.076^{* *} \\
(0.040,0.112)\end{array}$ & $\begin{array}{l}0.024 \\
(-0.015,0.063)\end{array}$ & $\begin{array}{l}0.065^{* *} \\
(0.041,0.088)\end{array}$ & $\begin{array}{l}0.035^{*} \\
(0.008,0.062)\end{array}$ \\
\hline Gini 2004: Q2 & $\begin{array}{l}-0.01 \\
(-0.042,0.021)\end{array}$ & $\begin{array}{l}0.036^{* *} \\
(0.013,0.060)\end{array}$ & $\begin{array}{l}0.053^{* *} \\
(0.018,0.088)\end{array}$ & $\begin{array}{l}0.048^{*} \\
(0.010,0.085)\end{array}$ & $\begin{array}{l}0.019 \\
(-0.003,0.042)\end{array}$ & $\begin{array}{l}0.018 \\
(-0.007,0.042)\end{array}$ \\
\hline Gini 2004: Q4 & $\begin{array}{l}0.008 \\
(-0.026,0.041)\end{array}$ & $\begin{array}{l}-0.001 \\
(-0.026,0.025)\end{array}$ & $\begin{array}{l}0.022 \\
(-0.016,0.060)\end{array}$ & $\begin{array}{l}0.011 \\
(-0.031,0.052)\end{array}$ & $\begin{array}{l}-0.021 \\
(-0.047,0.006)\end{array}$ & $\begin{array}{l}-0.007 \\
(-0.037,0.023)\end{array}$ \\
\hline $\begin{array}{l}\text { Gini 2004: Q5 (Highest } \\
\text { inequality) }\end{array}$ & $\begin{array}{l}-0.007 \\
(-0.057,0.044)\end{array}$ & $\begin{array}{l}-0.007 \\
(-0.041,0.027)\end{array}$ & $\begin{array}{l}-0.006 \\
(-0.056,0.045)\end{array}$ & $\begin{array}{l}0.02 \\
(-0.035,0.074)\end{array}$ & $\begin{array}{l}-0.032 \\
(-0.067,0.002)\end{array}$ & $\begin{array}{l}-0.061^{* *} \\
(-0.100,-0.023)\end{array}$ \\
\hline $\begin{array}{l}\text { Gini 1986: Q1 (Lowest } \\
\text { inequality) }\end{array}$ & $\begin{array}{l}0.025(-0.007 \\
0.058)\end{array}$ & $\begin{array}{l}0.023(-0.002 \\
0.047)\end{array}$ & $\begin{array}{l}0.062 * *(0.024 \\
0.100)\end{array}$ & $\begin{array}{l}0.075^{* *}(0.036 \\
0.114)\end{array}$ & $\begin{array}{l}0.024(-0.0005 \\
0.048)\end{array}$ & $\begin{array}{l}0.045^{* *}(0.017 \\
0.074)\end{array}$ \\
\hline Gini 1986: Q2 & $\begin{array}{l}0.013(-0.019 \\
0.045)\end{array}$ & $\begin{array}{l}0.024 *(0.0004 \\
0.047)\end{array}$ & $\begin{array}{l}0.049 * *(0.013 \\
0.085)\end{array}$ & $\begin{array}{l}0.075^{* *}(0.037 \\
0.114)\end{array}$ & $0.026 *(0.002,0.049)$ & $\begin{array}{l}0.018(-0.009 \\
0.046)\end{array}$ \\
\hline Gini 1986: Q4 & $\begin{array}{l}-0.050 * *(-0.082 \\
-0.018)\end{array}$ & $\begin{array}{l}-0.006(-0.030 \\
0.019)\end{array}$ & $\begin{array}{l}0.033(-0.0002, \\
0.067)\end{array}$ & $\begin{array}{l}0.011(-0.027 \\
0.049)\end{array}$ & $\begin{array}{l}0.003(-0.021 \\
0.028)\end{array}$ & $\begin{array}{l}0.003(-0.022 \\
0.028)\end{array}$ \\
\hline $\begin{array}{l}\text { Gini 1986: Q5 (Highest } \\
\text { inequality) }\end{array}$ & $\begin{array}{l}-0.055^{* *}(-0.087 \\
-0.024)\end{array}$ & $\begin{array}{l}-0.008(-0.031, \\
0.016)\end{array}$ & $\begin{array}{l}0.033(-0.010 \\
0.075)\end{array}$ & $\begin{array}{l}0.006(-0.032, \\
0.045)\end{array}$ & $\begin{array}{l}0.004(-0.020, \\
0.028)\end{array}$ & $\begin{array}{l}-0.022(-0.055, \\
0.011)\end{array}$ \\
\hline
\end{tabular}

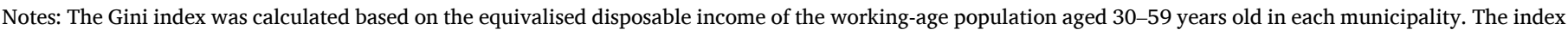

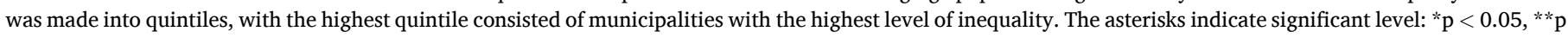
$<0.01$.

and $85+$ ), among whom we observed a number of distinct and differing patterns regarding the effects of income inequality on mortality (Edvinsson et al., 2013).

Our current findings show that higher income inequality at the municipality level, i.e. higher Gini index, is correlated with lower mortality in some age groups. These findings do not confirm the hypothesis of an income inequality effect. Similar findings have been reported elsewhere, for example in Switzerland (Clough-Gorr et al., 2015) and Spain (Regidor et al., 2015). It is difficult to make direct comparisons between studies due to differing definitions of the Gini index, different variables at the individual level and higher that are controlled for in the analysis, and importantly, the level of aggregation. The results are sensitive to variable operational definitions and how the regression models are built. Clough-Gorr et al., studying 4.7 million Swiss citizens in 2740 municipalities in the 2000 census, observed a lower risk of mortality for those who lived in municipalities with a high Gini index quintile. Note, however, that Clough-Gorr et al. have not included individual incomes in the models. In line with our observations in Sweden, Clough-Gorr et al. also reported a higher Gini index in larger cities. The average Gini in Switzerland was much higher compared to that observed in Sweden (mean Gini of 0.377 in 2000 in Switzerland as compared to 0.2929 in 2004 in Sweden in our dataset) (Clough-Gorr et al., 2015). The difference in the average Gini between the two studies, however, needs to be interpreted carefully. The way we calculated Gini based on the working-age population (30-60 years) as done by Elstad (2011), might make it incomparable with Gini reported in other studies where it is calculated based on the income distribution in the whole population. Using the national census register in Spain, Regidor et al. conducted a seven-year prospective study on a national sample of over 28 million people to investigate the effect of income inequality and per capita income of area of residence at the provincial level on mortality. They reported the lowest overall and cause-specific mortality rate of cancer and external causes, but not of cardiovascular disease, among residents in the poorest provinces. The study, however, shows no relationship between income inequality at provincial level and mortality (Regidor et al., 2015). In contrast to these other studies, Elstad (2011) finds an association between higher mortality and higher income inequality, measured using the Gini index in 35 Norwegian regions, even after adjusting for differences in regional socioeconomic and population structures (Elstad, 2011).

One might hypothesise that living in an unequal area potentially carries health benefits, especially if the poor people living alongside a wealthier population have adopted their healthier lifestyle. This hypothesis might hold true, subject to the wealthier segment of the population having a better education level and a healthier lifestyle; such as reduced cigarette consumption, more physical activity, lower blood pressure and lower cholesterol levels. Another hypothesis might be related to the availability and accessibility of infrastructures in the wealthier municipalities that are also often regarded as unequal municipalities, that benefit all the residents of the municipalities. Despite our effort to use region family to control for these differences between municipalities, it might be that the region family variable is not 


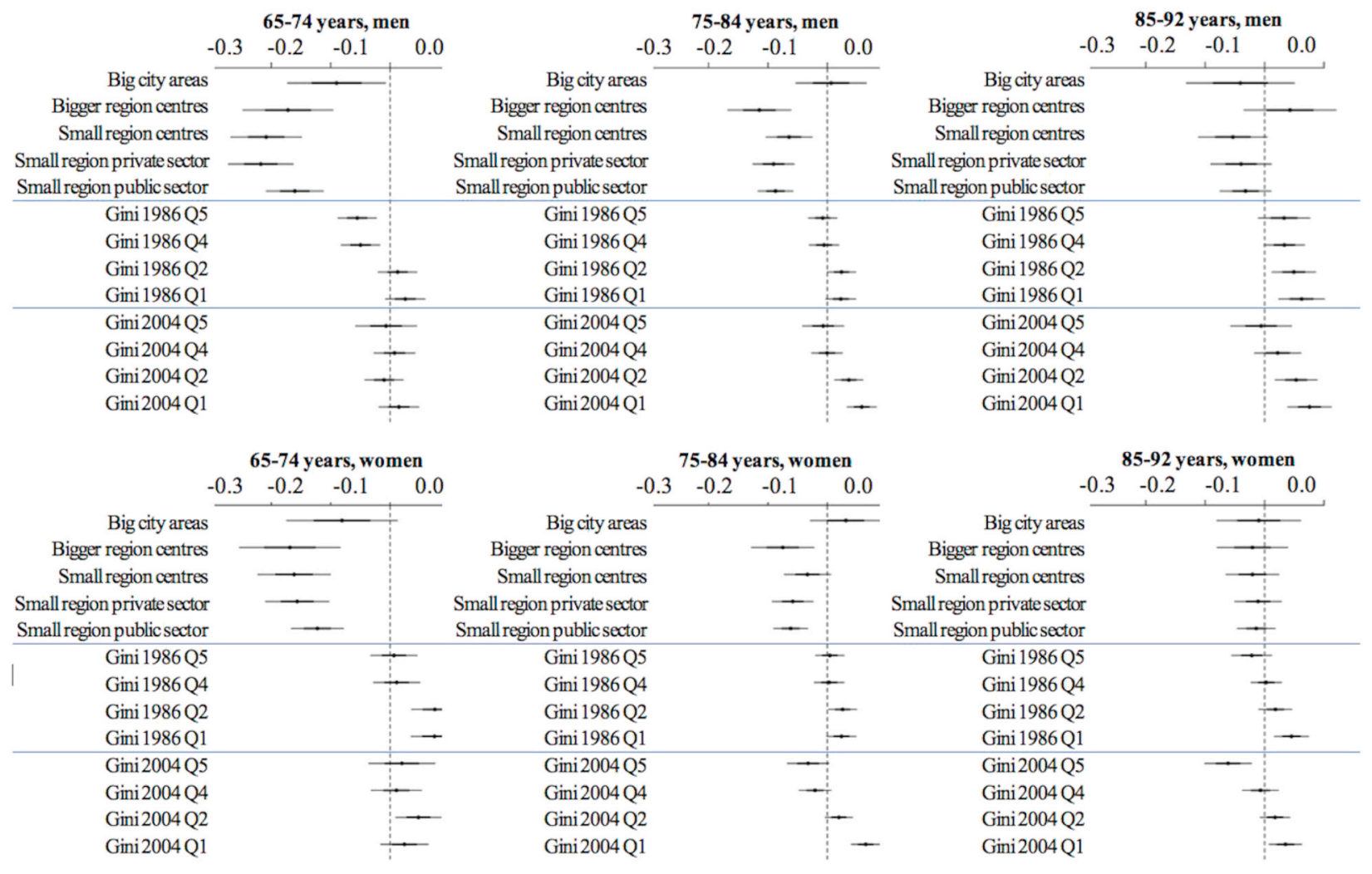

Fig. 2. Income inequality and old-age mortality among older Swedish population (controlled for individual disposable income and other individual and municipality-level factors).

sufficient for capturing differences in the (health) infrastructure availability and accessibility between municipalities.

Another possible explanation for the different effects of income inequality on mortality reported in different studies is the appropriate level of aggregation when assessing income inequality. In their review, Subramanian and Kawachi (2004) stressed the importance of geographical scale for the relation between income inequality and health (Subramanian and Kawachi, 2004). Negative findings similar to ours were reported by Regidor et al. (2015) in Spain, who explored the effects of provincial-level income inequality and mortality (Regidor et al., 2015). They argued that analysis of smaller geographical aggregations, such as census tracts or neighbourhoods, might be needed to reveal the true effect of area-level income inequality and mortality (Regidor et al., 2015).

The influence on old age mortality from income inequality in the surrounding geographical area may act on different levels, from the closest neighbourhood to the regional and even national level and the choice of geographical level for the analyses will most likely capture different mechanisms, at least to some extent. In this study, we have addressed the possible influence from the intermediate municipal level rather than from neighbourhood or regional levels. Hence, we are focusing not only on the potential impact from the income composition among those who live very close, but also on the influence from the income inequality in the wider administrative unit. We estimated the Gini index at the municipality level, at which population size differs considerably from fewer than 10,000 in many small municipalities in northern Sweden to over 100,000 in the 12 largest municipalities (the three largest municipalities being Stockholm with a population in 2004 of 765,582, Gothenburg with 481,523, and Malmö with 268,791) (Statistics Sweden, 2019). As the mechanisms through which income inequality exerts its effect upon smaller and larger municipalities (where populations are more segregated) might differ, the level of aggregation could be an important characteristic for estimating associations between income inequality and mortality. Gerdtham and Johannesson (2004), however, found no association of income inequality on mortality at higher levels of aggregation in Sweden (Gerdtham and Johannesson, 2004). An alternative would have been to include the even larger local labour market regions (defined by commuting patterns), but since we are focusing on a people that almost exclusively have left the labour force, we believe that the municipality level rather than commuting regions better capture the region of everyday activity, interaction and influence from the socio-economic characteristics in the geographical surroundings.

\section{The effects of individual-level variables on old-age mortality}

The positive relationship between income and health - i.e., higher income results in better health - is well-established and confirms what we observed in our study. Individualised disposable income seems to have little effect in the oldest age group, indicating a diminishing association between income and health as individuals age. For the oldest age group, disposable income might be less of a distinguishing factor than education. As a large proportion in this age group were widowed, using disposable income as an individual economic standard indicator is problematic. In their study of Swedish municipalities in the 1990s, Gerdtham and Johannesson (2004) found that mortality decreased with increasing individual income (Gerdtham and Johannesson, 2004). They did not, however, find any support for either the relative income hypothesis or the income inequality hypothesis as defined by Wagstaff and van Doorslaer (Wagstaff and van Doorslaer, 2000). Though the income-health relationship is well-established, the association between income inequality and health is independent of the income-health relationship (Subramanian and Kawachi, 2004). 


\section{The role of contextual variables}

The potential confounding of regional differences needs to be controlled for in studies assessing income inequality and mortality (Subramanian and Kawachi, 2004). In this study, we used median municipality income and region family as proxies for contextual/municipality-level variables. Municipalities differ in compositional factors that might influence the wealth and health of their populations. The underlying social and economic structure in the municipality can influence the level of wealth and its distribution - and therefore income inequality - and the level of morbidity and mortality in the population, thus potentially confounding the association between income inequality and health outcomes. Adjusting for the region family characteristic changed the association between Gini index and mortality, indicating that income inequality and mortality differed significantly across different region families. In contrast to our findings, Elstad (2011) did not observe any significant impact of regional-level social and economic characteristics on the association between income inequality and mortality (Elstad, 2011). The results in this study illustrate the importance of correct statistical modelling. Controlling for regional characteristics resulted in substantial changes in the results for some groups. There are important differences between studies in how the analyses have been performed and which variables are controlled for, making any comparisons difficult.

\section{The long-term effects of income inequality on old-age mortality}

It might be possible that the effects of a lagged Gini index were nonsignificant or marginally significant because of the very low and homogenous 1986 Gini index, suggestive of very low-income inequality across different municipalities in Sweden at that time. A meta-analysis conducted by Kondo et al. (2009) on 19 cross-sectional studies showed that the association between income inequality and health outcome was much stronger among studies with a higher Gini of over 0.3 (Kondo et al., 2009). Our findings could be seen as supportive of the threshold effect hypothesis in Sweden. Those who were in old age in the early 21 st century had lived their adult years in a society with very low levels of income inequality. The trajectory towards more inequality may in turn change the associations for coming generations of older people, but this can only be known in the future. Still, our results here imply that the association between income inequality and mortality in old age can act in the opposite direction at municipality level. The mechanisms for these associations are not completely clear, however.

\section{Strengths and limitations}

In this study, we had access to high-quality linked register/national data on all older individuals living in Sweden during the period 1986-2009. Having access to this longitudinal information allowed us to create lagged terms for the Gini index, which enabled us to investigate the long-term effects of income equality on health. The ability to control for individual income, the use of longitudinal data, and the use of lagged term of income inequality information are the three major strengths of this study. Subramanian and Kawachi (2004) identify the lack of these controls as a limitation in existing studies on income inequality and health (Subramanian and Kawachi, 2004). In addition, in this study we focused on the effects of income inequality in old age, which are not yet well-studied.

Several limitations need to be kept in mind when interpreting the results of this study. Despite our attempt to use region family as a proxy to capture the contextual variables at the municipality level, other contextual-level variables that could influence the different mortality risks observed across municipalities were not controlled for. We did not control for municipality size or the proportion of older people in a municipality, both of which might influence the availability of social and health services provided by the municipality. Different municipalities might have different infrastructure development that could influence the population's health. We also did not assess the effect of neighbourhood or residential segregation.

\section{Conclusions}

Our study found no immediate or lagged effect of income inequality on increasing old-age mortality at the municipality level in Sweden. In some age cohorts, we even observed lower mortality among those living in unequal municipalities. However, this study shows the importance of regional effects as a potential confounder in measuring the association between income inequality and old-age mortality. Regional differences in infrastructure and health facilities and services should therefore be considered. This study reiterates that it is economic conditions at the individual level rather than income inequality in the municipality that impacts more on mortality among the contemporary Swedish population. This might be explained by the low (albeit increasing in recent years) level of income inequality in Sweden, particularly at the time lags.

\section{Authors contributions}

Conceptualization: Sören Edvinsson, Nawi Ng, Erling Lundevaller, Gunnar Malmberg.

Methodology: Sören Edvinsson, Nawi Ng, Erling Lundevaller, Gunnar Malmberg.

Formal analysis and investigation: Erling Lundevaller.

Writing - original draft preparation: Sören Edvinsson, Nawi Ng.

Writing - review and editing: : Sören Edvinsson, Nawi Ng, Erling Lundevaller, Gunnar Malmberg.

Funding acquisition: Sören Edvinsson, Nawi Ng, Erling Lundevaller, Gunnar Malmberg.

\section{Funding}

The Swedish Research Council Vetenskapsrådet supported this research (Dnr 2012-00892).

\section{Compliance with ethical standard}

We obtained the ethical approval for the analysis of the Linnaues Database (Dnr 07. 142Ö) from the regional ethics committee in Umeå.

\section{Declaration of competing interest}

The authors declare that they have no conflict of interest.

\section{Acknowledgements}

We acknowledge the Statistics Sweden and the Swedish National Board of Health and Welfare for their contribution in setting up the Linnaeus Database.

\section{Appendix A. Supplementary data}

Supplementary data to this article can be found online at https://doi. org/10.1016/j.healthplace.2020.102384.

\section{References}

Arber, S., Fenn, K., Meadows, R., 2014. Subjective financial well-being, income and health inequalities in mid and later life in Britain. Soc. Sci. Med. 100, 12-20.

Blakely, T.A., Kennedy, B.P., Glass, R., Kawachi, I., 2000. What is the lag time between income inequality and health status? J. Epidemiol. Community Health 54, 318-319.

Bor, J., Cohen, G.H., Galea, S., 2017. Population health in an era of rising income inequality: USA, 1980-2015. Lancet 389, 1475-1490. 
Clough-Gorr, K.M., Egger, M., Spoerri, A., 2015. A Swiss paradox? Higher income inequality of municipalities is associated with lower mortality in Switzerland. Eur. J. Epidemiol. 30, 627-636.

Dahl, E., Ivar Elstad, J., Hofoss, D., Martin-Mollard, M., 2006. For whom is income inequality most harmful? A multi-level analysis of income inequality and mortality in Norway. Soc. Sci. Med. 63, 2562-2574.

Dannefer, D., 2003. Cumulative advantage/disadvantage and the life course: crossfertilizing age and social science theory. J. Gerontol. B Psychol. Sci. Soc. Sci. 58 S327-S337.

Edvinsson, S., Lundevaller, E.H., Malmberg, G., 2013. Do unequal societies cause death among the elderly? A study of the health effects of inequality in Swedish municipalities in 2006. Glob. Health Action 6. https://doi.org/10.3402/gha. v3406i3400.19116.

Elstad, J.I., 2011. Does the socioeconomic context explain both mortality and income inequality? Prospective register-based study of Norwegian regions. Int. J. Equity Health 10, 7.

Gerdtham, U.-G., Johannesson, M., 2004. Absolute income, relative income, income inequality, and mortality. J. Hum. Resour. 39, 228-247.

Henriksson, G., Allebeck, P., Weitoft, G.R., Thelle, D., 2006. Income distribution and mortality: implications from a comparison of individual-level analysis and multilevel analysis with Swedish data. Scand. J. Publ. Health 34, 287-294.

Henriksson, G., Weitoft, G.R., Allebeck, P., 2010. Associations between income inequality at municipality level and health depend on context - a multilevel analysis on myocardial infarction in Sweden. Soc. Sci. Med. 71, 1141-1149.

Kim, K.T., 2017. The relationships between income inequality, welfare regimes and aggregate health: a systematic review. Eur. J. Publ. Health 27, 397-404.

Kondo, N., Sembajwe, G., Kawachi, I., van Dam, R.M., Subramanian, S.V., Yamagata, Z, 2009. Income inequality, mortality, and self rated health: meta-analysis of multilevel studies. BMJ 339, b4471.
Malmberg, G., Nilsson, L.G., Weinehall, L., 2010. Longitudinal data for interdisciplinary ageing research. Design of the Linnaeus Database. Scand. J. Publ. Health 38, 761-767.

Martinson, M.L., 2012. Income inequality in health at all ages: a comparison of the United States and England. Am. J. Publ. Health 102, 2049-2056.

Mellor, J.M., Milyo, J., 2003. Is exposure to income inequality a public health concern? Lagged effects of income inequality on individual and population health. Health Serv. Res. 38, 137-151.

NUTEK, 2007. Regioner Och Arbetsmarknad. Metoder För Regionindelningar Utifrån Arbetsmarknadens Funktionssätt. NUTEK, Stockholm.

Pickett, K.E., Wilkinson, R.G., 2014. Income inequality and health: a causal review. Soc. Sci. Med. 128, 316-326.

Regidor, E., Vallejo, F., Giraldez-Garcia, C., Ortega, P., Santos, J.M., Astasio, P., de la Fuente, L., 2015. Low mortality in the poorest areas of Spain: adults residing in provinces with lower per capita income have the lowest mortality. Eur. J. Epidemiol. $30,637-648$.

Statistics Sweden, 2019. Population Statistics in 2004. Stockhom.

Subramanian, S.V., Kawachi, I., 2004. Income inequality and health: what have we learned so far? Epidemiol. Rev. 26, 78-91.

Wagstaff, A., van Doorslaer, E., 2000. Income inequality and health: what does the literature tell us? Annu. Rev. Publ. Health 21, 543-567.

Wilkinson, R.G., Pickett, K., 2009. The Spirit Level: Why More Equal Societies Almost Always Do Better? Allen Lane, London.

Wilkinson, R.G., Pickett, K.E., 2006. Income inequality and population health: a review and explanation of the evidence. Soc. Sci. Med. 62, 1768-1784.

Zheng, H., 2012. Do people die from income inequality of a decade ago? Soc Sci Med 75 (1), 36-45. 